\title{
BMJ Open Effectiveness of government anti- smoking policy on non-smoking youth in Korea: a 4-year trend analysis of national survey data
}

\author{
Jueun Kwak, ${ }^{1}$ Hyunsuk Jeong, ${ }^{2}$ Sungha Chun, ${ }^{3}$ Ji Hoon Bahk, ${ }^{1}$ Misun Park, ${ }^{4}$ \\ Youngseol Byun, ${ }^{1}$ Jina Lee, ${ }^{1}$ Hyeon Woo Yim ${ }^{2,5}$
}

To cite: Kwak J, Jeong $\mathrm{H}$, Chun S, et al. Effectiveness of government anti-smoking policy on non-smoking youth in Korea: a 4-year trend analysis of national survey data. BMJ Open 2017;7:e013984. doi:10.1136/ bmjopen-2016-013984

- Prepublication history for this paper is available online. To view these files please visit the journal online (http://dx.doi org/10.1136/bmjopen-2016013984).

Received 20 September 2016 Revised 18 April 2017 Accepted 16 May 2017

\section{(1) CrossMark}

${ }^{1}$ Catholic Medical Center, Seoul, Republic of Korea

${ }^{2}$ Department of Preventive Medicine, College of Medicine,

The Catholic University of Korea, Seoul, Republic of Korea

${ }^{3}$ College of Medicine, The Catholic University of Korea, Seoul, Republic of Korea ${ }^{4}$ Clinical Research Coordinating Center, Catholic Medical Center, Republic of Korea

${ }^{5}$ Clinical Research Coordinating Center, Catholic Medical Center, Republic of Korea

Correspondence to Dr Hyeon Woo Yim; y1693@ catholic.ac.kr

\section{ABSTRACT}

Objectives Since the Health Promotion Act was introduced in Korea in 1995, anti-smoking policies and regulations have undergone numerous revisions, and non-smoking areas have gradually been expanded. The purpose of this study was to examine the impact of a partial legislative ban on adolescent exposure to secondhand smoke using objective urinary cotinine levels in a nationwide representative sample.

Methods Urine cotinine levels were measured in the Korea National Health and Nutrition Examination Survey from 2008 to 2011. This study was a trend analysis of 4 years of national survey data from 2197 Korean youth aged 10-18 years. Among non-smokers, the 75th percentile urinary cotinine level was estimated. We also considered the number of household smokers.

Results The 75th percentile urine cotinine level of nonsmokers showed a significant decreasing trend from 2008 to 2011 , from 15.47 to $5.37 \mathrm{ng} / \mathrm{mL}$, respectively. Urine cotinine did not decline significantly in non-smokers living with smokers during the study period. The results did not show a statistically significant reduction in smoking rate in adolescents from 2008 to 2011, although there was a trend towards a decrease $(p=0.081)$.

Conclusions Based on urine cotinine levels, governmentinitiated anti-smoking policies have only been effective among highly exposed non-smoking adolescents during the study period. Further study needs to evaluate whether or not the legislative ban affects domestic smoking exposure.

\section{BACKGROUND}

Tobacco smoke includes about 4000 toxic chemicals, along with 50 carcinogens. Moreover, sidestream smoke, the major component of environmental tobacco smoke (ETS), has a higher concentration of harmful chemicals $^{1}$ and consists of smaller particles than mainstream smoke. ${ }^{2}$ Children, whose airways are still developing, are more vulnerable to ETS than adults. With regard to the ETS exposure outcomes of school-aged children, a great deal of strong evidence has been reported. Studies have suggested a variety of

\section{Strengths and limitations of this study}

This study was a 4-year trend analysis of national survey data from Korea to evaluate the association between a partial legislative smoking ban and smoking exposure in youth.

- Smoking status in youth was classified according to both self-report and urinary cotinine levels and environmental tobacco smoke (ETS) exposure was measured by urinary cotinine level.

- Since the study period was only 4 years, there were limitations to observing a statistically significant trend.

- Because our data were not longitudinal, a decreasing cotinine trend was not derived from repeated measures data from the same individuals.

ETS-associated health problems such as respiratory, cardiovascular and neurobehavioral issues. $^{2-4}$

Approximately $12.5 \%$ of never-smoking adolescents are exposed to ETS. ${ }^{5}$ Smoking exposure from smoking parents or peers is an important aspect of exposure to ETS among non-smoking adolescents. ${ }^{6}$ Comprehensive smoke-free policies can reduce ETS exposure among non-smokers.

Several studies have shown that exposure to secondhand smoke in workplaces, public places, bars and restaurants was reduced after legislation prohibiting public smoking among adults. ${ }^{7-9}$ A previous study was conducted in Spain to evaluate whether imposing a complete ban on smoking in enclosed public places, on public transport, and in the workplace could protect non-smoking adolescents from secondhand smoke exposure using a cohort sample. ${ }^{10}$ Many studies have evaluated the effects of legislation on smoking indoors, including a complete smoking ban in bars and restaurants or less comprehensive smoking bans, such as those allowing 
smoking in designated rooms or areas. In particular, it is difficult to determine whether school-aged children can reduce exposure to secondhand smoke due to a legislative smoking ban because schools have been traditionally thought of as non-smoking areas, regardless of the smoking policy.

It is uncertain whether existing or past Korean tobacco control policies effectively protect children. Some have argued that policies cannot be effective in protecting children because their predominant exposure is in the home, beyond the reach of government control. ${ }^{2}$

Anti-smoking policies can influence communities in different ways. ETS exposure in children is not negligible; therefore, it is necessary to estimate the effectiveness of government tobacco control policies in protecting children from ETS. Thus, the objective of the present study was to investigate the impact of a partial legislative ban on adolescent exposure to secondhand smoke using objective urinary cotinine levels in a nationwide representative sample. We also explored how anti-smoking policies have changed smoking prevalence among Korean school-aged children.

\section{METHODS}

\section{Tobacco control policies in Korea}

Since the Health Promotion Act of 1995 introduced the first national anti-smoking regulations in Korea, a partial smoking ban in some public places, public transportation and workplaces was initiated.

The anti-smoking policy restricts advertisement of tobacco products and sales to minors under 19 years of age and increased cigarette cost in $1995^{17}$. Although limited and considered to be ineffective by some, it is clear that Korea's government-led anti-smoking movement achieved a substantial reduction in smoking prevalence from nearly $70 \%$ during the 1980 s to $42.1 \%$ in $2013 .{ }^{11} 12$ Korean anti-smoking policies have undergone numerous revisions and expansions.

The WHO Framework Convention on Tobacco Control (FCTC), ratified by Korea at the end of 2005, was a rigorous and systematic worldwide enforcement policy on tobacco control. Subsequently, the Ministry of Health and Welfare of South Korea adopted more aggressive measures according to the WHO's guideline, MPOWER (Monitoring, Protect, Offer, Warn, Enforcement, and Raise). ${ }^{13} \quad 14$ Korea introduced the National Quitline Service in 2006. The number of designated non-smoking areas was extended to all stores regardless of size and also to elevators, aisles and certain outdoor spaces in 2008. In 2010 , local governments were given the power to enact ordinances on outdoor smoking restrictions. In 2011, some public places were designated as completely smokefree, including government offices, nurseries, medical facilities, schools, large restaurants and bars. The policy changed from a partial ban to a complete smoking ban in 2011. In 2015, all enclosed public spaces were designated as completely smoke-free (figure 1 ). ${ }^{13}$

\section{Data and study population}

This study was a trend analysis of 4 years of national survey data from Korea to evaluate the association between a legislative smoking ban and smoking exposure in youth. All data were derived from the fourth (2008-2009) and fifth (2010-2011) Korea National Health and Nutrition Examination Survey (KNHANES) conducted by the Korean Centre for Disease Control and Prevention. This study covered the transition period from a partial ban to a complete ban (2008-2011). Subjects were collected using stratified, clustered, multi-stage probability sampling ${ }^{15}$ based on geographic area, age and sex to represent the whole Korean population. Information about individual health behaviours and socioeconomic characteristics were collected by structured questionnaire and bio-clinical data, including urine and blood samples, were collected by a trained specialist. The unweighted response rates of the KNHANES surveys were $74.3 \%, 79.2 \%, 77.5 \%$ and $76.1 \%$ in 2008, 2009, 2010 and 2011, respectively. In the present study, of 4326 subjects aged 10-18 years, 2401 were excluded due to missing urine cotinine measurements. Finally, a total of 2197 subjects (902 in 2008, 617 in 2009, 340 in 2010 and 338 in 2011) were included. The KNHANES surveys have been reviewed by the Institutional Review Board of Centres for Disease Control \& Prevention of Korea (KCDC) on the basis of domestic and foreign laws and guidelines including the Declaration of Helsinki, bioethics laws and the National Security Act. Written informed consent was received from the participants' legal guardians. The KCDC released de-identified KNHANES data. This study received approval from the Institutional Review Board of the Catholic University of Korea (MC15EISI0097) for data analysis.

\section{Smoking status determination}

Two methods can be used to determine adolescent smoking status from the KNHANES. One measure involves using self-reported answers to questions such as 'Have you ever smoked?' and 'During the past 30 days, how many days did you smoke cigarettes?'. The other uses measurements of cotinine level. However, considering the under-reporting bias associated with adolescent smoking, we decided to apply a combined method of questionnaires and bio-clinical measures. Thus, children with a urine cotinine level above $100 \mathrm{ng} / \mathrm{mL}$ were considered to be current smokers, regardless of self-reporting, and children who reported smoking in the most recent 30 days were considered to be current smokers, regardless of urinary cotinine level. A total of 247 subjects with missing self-report answers on smoking habits were categorised based solely on urinary cotinine level. Children aged 10-11 years not interviewed about smoking habits were preferentially considered non-smokers and classified as current smokers only if their urinary cotinine level was above the cut-off value of $100 \mathrm{ng} / \mathrm{mL}$. Additionally, we separated children with a urine cotinine level $<0.01 \mathrm{ng} /$ $\mathrm{mL}$ (minimum level of detection) into an 'undetectable' group, belonging to the non-smoking group. 


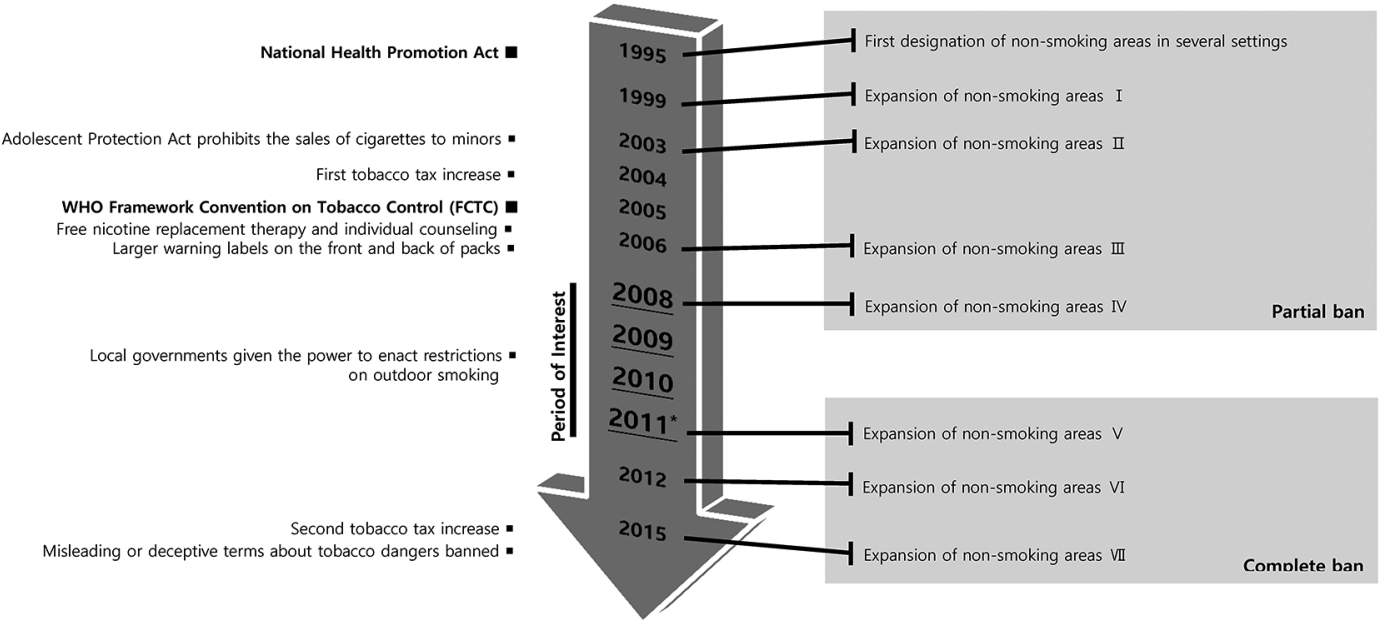

Figure 1 Representative Korean anti-smoking policies including smoke-free air policies over the past decade. In 1995, the first non-smoking area designation was implemented in large buildings, theatres, stores, hospitals, schools, gyms and public transportation as a partial smoking ban (separate smoking areas). In 1999, non-smoking areas were created in public baths and ceremony halls. In 2003, non-smoking areas were expanded to game rooms, large restaurants, comic book stores, government buildings and nursery schools. The WHO Framework Convention on Tobacco Control (FCTC) began in 2005 and in 2006 , and factories, local government buildings and indoor workplaces were added to the list of buildings with non-smoking areas. A fourth expansion was implemented to include elevators, aisles in buildings, restrooms and other public spaces in 2008. In 2011, to reduce passive smoking, a complete smoking ban was applied in schools, kindergartens, daycare centres and medical facilities, with penalties for both facility managers and individual smokers, and other public places were added to the partial ban list. The sixth expansion measure in 2012 included small restaurants in the complete smoking ban; finally, in 2015, smoking was prohibited in all stores. *A new education policy, The Student Human Rights Ordinance, came into effect starting in Gyeonggido (a rural area).

\section{Measurement of urinary cotinine}

Urinary samples were collected at the time of the health examination. The cotinine level was measured by gas chromatography-mass spectrometry using a Perkin Elmer Clarus 600T (Perkin-Elmer, Turku, Finland) spectrometer $^{16}$ and was reviewed by a central quality control centre. The detection limit of urinary cotinine was $1.26 \mathrm{ng} / \mathrm{mL}$. For internal quality assurance and control purposes, standard reference materials were used (ClinChek, Recripe, Munich, Germany), which showed that the coefficients of variation were $3.43-9.11 \%$ in 2008 and $0.79-8.17 \%$ in 2009. The German External Quality Assessment Scheme (G-EQUAS), operated by Friedrich Alexander University, has a standard protocol for measuring urinary cotinine; this was used for external quality assurance and controls, and all specimens met these standards. ${ }^{17}$

\section{Study variables}

Demographic variables of interest were age, sex, residence area, monthly household income and number of current smokers in the family, which were considered to be possible factors influencing ETS exposure levels of children.

Age was divided into three groups: 10-12, 13-15 and 16-18 years. Since Seoul, which is the capital city of Korea, is quite different from other cities in terms of policy implementation and population density, residence area was classified into Seoul, other cities or rural areas.
Household income was calculated using the minimum cost of living (MCL) measured by the Ministry of Health and Welfare based on family size and inflation by year and was divided into low (<120\% MCL), middle (120-250\%) and high $(\geq 250 \%)$.

We collected information on household smoking status, including grandparents, parents and siblings.

\section{Statistical analysis}

All statistical analyses were performed using SAS 9.3 (SAS Institute, Cary, North Carolina, USA). The cotinine levels in 2009 were obtained in a half sample of participants for an administrative reason. The results of analyses in 2009 represent estimates in half of the whole Korean student population. All statistics were calculated using sample weights assigned to sample participants. The sample weights were constructed to represent the Korean population by accounting for the complex survey design, survey non-response and post-stratification.

Sociodemographic variables were expressed as weighted percentages and 95\% CIs, and differences in characteristics across survey periods were calculated using the Rao-Scott $\chi^{2}$ test. Smoking prevalence rates with $95 \%$ CIs were calculated. The distribution of urinary cotinine level was skewed and was therefore log-transformed to estimate the 75 th percentile and $95 \%$ CI.

Since the government-initiated smoking ban might have a greater effect on higher exposure groups, the 75 th 
Table 1 Demographic characteristics of Korean school-aged children and adolescents from 2008 to 2011 according to the Korea National Health and Nutrition Examination Survey (KNHANES)

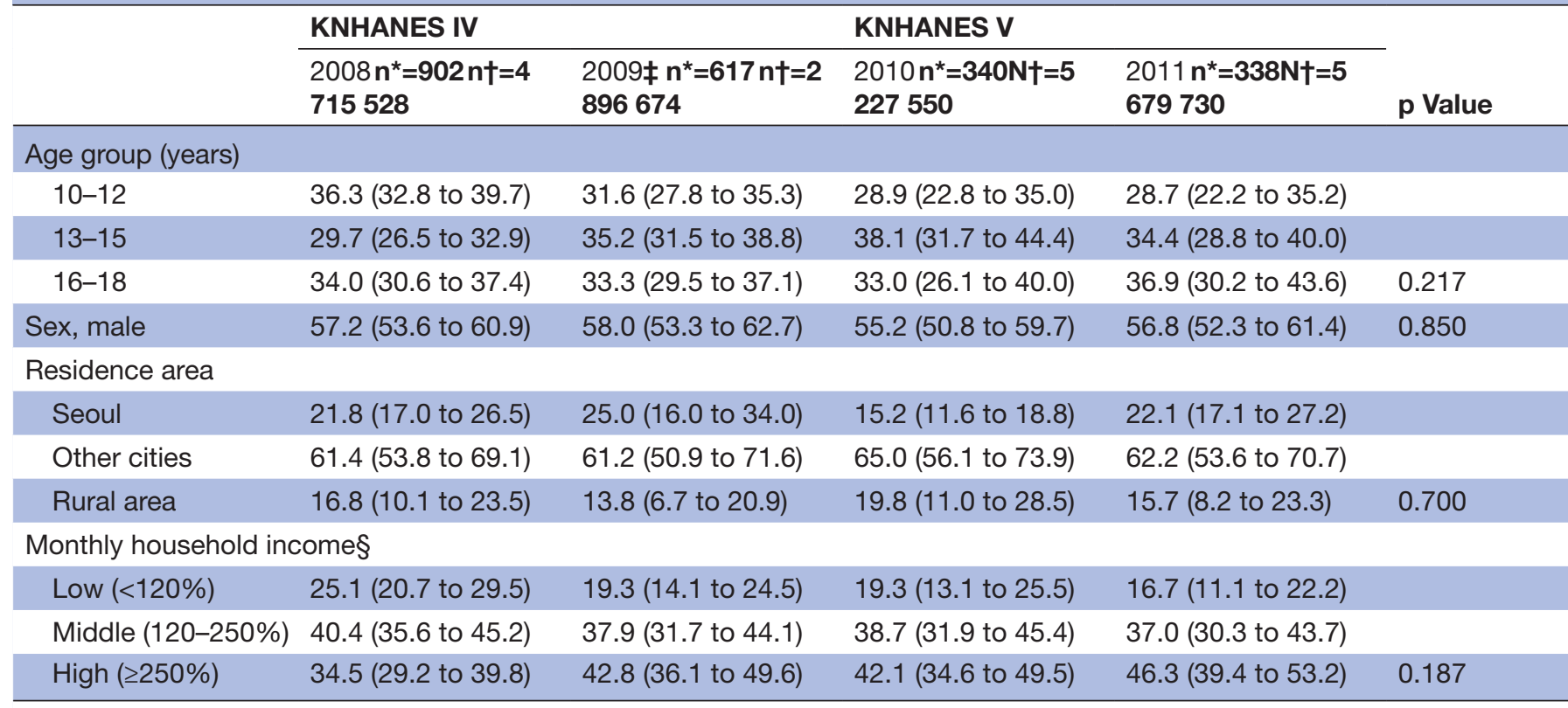

Data are presented as proportion $(95 \% \mathrm{Cl})$.

*Participants in the KNHANES IV, V.

†Estimated Korean population weighted by year.

$\ddagger$ The subjects in 2009 represent half of the whole student sample; for an administrative reason, the survey was conducted in the second half of the year.

$\S$ Calculated based on the minimum cost of living (MCL) measured by the government. MCL reflects family size and inflation each year.

percentile was selected as more appropriate than the median value for evaluating the influence of these policies.

The trend in urinary cotinine level change among non-smokers was analysed using simple linear regression (SURVEYREG) in the survey period. A temporal trend in the prevalence of current smokers over the 4-year study period was evaluated using univariate logistic regression (SURVEYLOGISTIC), and confidence intervals were constructed using the Wald method. A temporal trend in the prevalence of current smokers was examined excluding the 2011 data, since a period effect was shown in 2011. p Values for trends were determined by analyses after setting period as the continuous variable. All statistical significance was determined by a $\mathrm{p}$ value $<0.05$.

\section{RESULTS}

There were 902 study subjects in 2008, 617 in 2009, 340 in 2010 and 338 in 2011, representing an estimated 4.7 million, 2.9 million, 5.2 million and 5.7 million Korean school-aged children, respectively. Demographic characteristics including age, sex, residence area and household monthly income showed no differences during the 4-year period (table 1).

Smoking rate $(95 \% \mathrm{CI})$, defined by either self-reporting or urinary cotinine level above $100 \mathrm{ng} / \mathrm{mL}$, was estimated as $12.6 \%(9.6-15.5 \%)$ in $2008,10.0 \%(6.8-13.2 \%)$ in $2009,8.1 \%(4.6-11.7 \%)$ in 2010 and $15.7 \%$ (10.5-20.9\%) in 2011 (table 2).
Urinary cotinine levels in the 75th percentile decreased in the non-smoking group aged 10-18 years $(15.47 \mathrm{ng} /$ $\mathrm{mL}$ in $2008,11.96 \mathrm{ng} / \mathrm{mL}$ in $2009,9.26 \mathrm{ng} / \mathrm{mL}$ in 2010 and $5.37 \mathrm{ng} / \mathrm{mL}$ in 2011) (figure 2). The urinary cotinine level showed a significant decreasing trend only in the $10-12$-year-old group $(p<0.001)$. When subgroups were divided by gender, the 75 th percentile urinary cotinine level were significantly decreased in both groups. All residence area subgroups except the rural area group showed similar significant decreases over time. Among monthly household income subgroups, the 75 th percentile urinary cotinine level in both middle and high income subgroups showed a significant decreasing trend from 2008 to 2011 . When categorised according to the number of current smoking family members, the decreasing trend was significant only in children with no smokers in the family (figure 2).

The current smoking rates of Korean school-aged children showed a decreasing tendency from 2008 to 2010, although this was not statistically significant $(\mathrm{p}=0.081)$, and peaked at $15.7 \%$ in 2011 (table 3). A similar trend was observed in diverse subgroups according to age, sex and household monthly income. In residence area subgroups, the trend was noticeable. Cities other than Seoul showed a significant decreasing tendency from 2008 to 2010 and a peak of $18.0 \%$ in 2011. Neither Seoul nor the rural areas showed any decreasing tendency in smoking rates from 2008 to 2010. However, in 2011 the smoking rate decreased by $6.3 \%$ in Seoul and increased by $19.9 \%$ in rural areas (table 3 ). 
Table 2 Smoking prevalence rates of Korean school-aged children and adolescents from 2008 to 2011

\begin{tabular}{|c|c|c|c|c|c|}
\hline & \multicolumn{2}{|l|}{ KNHANES IV } & \multicolumn{3}{|l|}{ KNHANES V } \\
\hline & $\begin{array}{l}2008 n^{*}=902 N \dagger=4 \\
715528\end{array}$ & $\begin{array}{l}2009 \ddagger n *=617 n \dagger=2 \\
896674\end{array}$ & $\begin{array}{l}2010 n *=340 n \dagger=5 \\
227550\end{array}$ & $\begin{array}{l}2011 n^{*}=338 n \dagger=5 \\
679730\end{array}$ & p Value§ \\
\hline $\begin{array}{l}\text { Self-reported smoker with } \\
\text { cotinine }>100 \mathrm{ng} / \mathrm{mL}\end{array}$ & 6.7 (4.5 to 8.8$)$ & 5.6 (2.9 to 8.3$)$ & $1.9(0.2$ to 3.6$)$ & 9.0 (4.9 to 13.1$)$ & \\
\hline $\begin{array}{l}\text { Self-reported non-smoker } \\
\text { with cotinine }>100 \mathrm{ng} / \mathrm{mL}\end{array}$ & 4.8 (2.8 to 6.7$)$ & $2.4(1.0$ to 3.8$)$ & $4.2(1.5$ to 6.9$)$ & 6.1 (2.6 to 9.5$)$ & \\
\hline $\begin{array}{l}\text { Missing self-report with } \\
\text { cotinine }>100 \mathrm{ng} / \mathrm{mL}\end{array}$ & 0 & 0 & 0 & 0 & \\
\hline Subtotal & $12.6(9.6$ to 15.5$)$ & $10.0(6.8$ to 13.2$)$ & 8.1 (4.6 to 11.7$)$ & 15.7 (10.5 to 20.9$)$ & \\
\hline $\begin{array}{l}\text { Missing self-report with } \\
\text { cotinine } \leq 100 \mathrm{ng} / \mathrm{mL}\end{array}$ & 0.4 (0.0 to 0.9$)$ & 0 & $0.2(0.0$ to 0.7$)$ & 0 & \\
\hline Undetectable cotinineף & 21.3 (17.4 to 25.2 ) & 19.1 (14.9 to 23.3 ) & $6.3(2.7$ to 9.9$)$ & $3.5(1.3$ to 5.8$)$ & \\
\hline Subtotal & 87.4 (84.4 to 90.4$)$ & 90.0 (86.8 to 93.2) & 91.9 (88.3 to 95.4$)$ & 84.3 (79.1 to 89.5$)$ & 0.018 \\
\hline
\end{tabular}

Data are presented as proportion $(95 \% \mathrm{Cl})$.

${ }^{*}$ Participants in the KNHANES IV,V.

†Estimated Korean population weighted by year.

$\ddagger$ The cotinine levels in 2009 were obtained in a half sample of participants.

$\S$ The $\chi^{2}$ test was used to compare smoking status and date.

TA urinary cotinine level below 0.01 was considered to be undetectable.

\section{Discussion}

Many studies have explored the outcomes of multifaceted anti-smoking policies enacted by the government, but the research was mostly limited to examination of the smoking prevalence of adults or ETS exposure rates based on self-reporting. ${ }^{13-20}$ This might be because the primary concern of policy makers is reduction of adult smoking prevalence, which directly reflects regulation effects. Additionally, it is difficult to obtain objective values assessing ETS exposure at a national level. However, in 2008 the KNHANES began to collect data on the urinary cotinine level, a specific biomarker for tobacco smoke exposure. Thus, the present study was able to approach the study question more objectively.

One of the most important issues in studies of smoking prevalence is under-reporting bias, ${ }^{21}$ which is especially prominent in women and teenagers. Thus, we established a cut-off value of $100 \mathrm{ng} / \mathrm{mL}$ urinary cotinine and used it to determine smoking status. This was helpful for resolving the problem of under-reporting and improving the quality of ETS exposure measurement. Some studies have suggested a cut-off value for discrimination of smokers from non-smokers, but this value varies from 20 to $150 \mathrm{ng} / \mathrm{mL} .{ }^{22-25}$ Finally, based on the finding that urinary cotinine is always less than $100 \mathrm{ng} / \mathrm{mL}$ in non-smokers ${ }^{23}$ and that the reported cotinine half-life is similar in older children and adults, ${ }^{26}$ we used $100 \mathrm{ng} / \mathrm{mL}$ as a threshold value in adolescents. Approximately 25-50\% of current smokers reported being non-smokers on self-report. Adolescents who claimed to be non-smokers via self-reporting and had a urinary cotinine level $>100 \mathrm{ng} / \mathrm{mL}$ showed similar median and 75 th percentile cotinine levels to smokers. We compared the current smoking prevalence results in our study with those of the Korea Youth Risk Behaviour Web-based Survey conducted during the same period, which is considered to be the most realistic due to complete anonymity. The survey procedure protects respondents' privacy, which contributes to the accurate detection of delinquent behaviours (eg, smoking prevalence) compared with other interview surveys of Korean adolescents. ${ }^{27}$ The reported outcomes of the above survey and our study were very similar after applying the urine cotinine cut-off value for smoking status classification. Even when applying an alternative cut-off $(50 \mathrm{ng} / \mathrm{mL}$ or $150 \mathrm{ng} / \mathrm{mL}$ ), the observed decreasing trend in 75 th percentile urinary cotinine for non-smokers was similar between the surveys.

Urinary cotinine is a fairly accurate indicator of the level of passive smoking. ${ }^{23}$ Eighty percent of nicotine, the main component of cigarettes, is converted into cotinine in the body, which has a half-life of about 20 hours. Therefore, non-accumulative recent ETS exposure is easily assessed using urinary cotinine,$^{28} 29$ which makes it a good indicator for the effectiveness of smoking policies. 

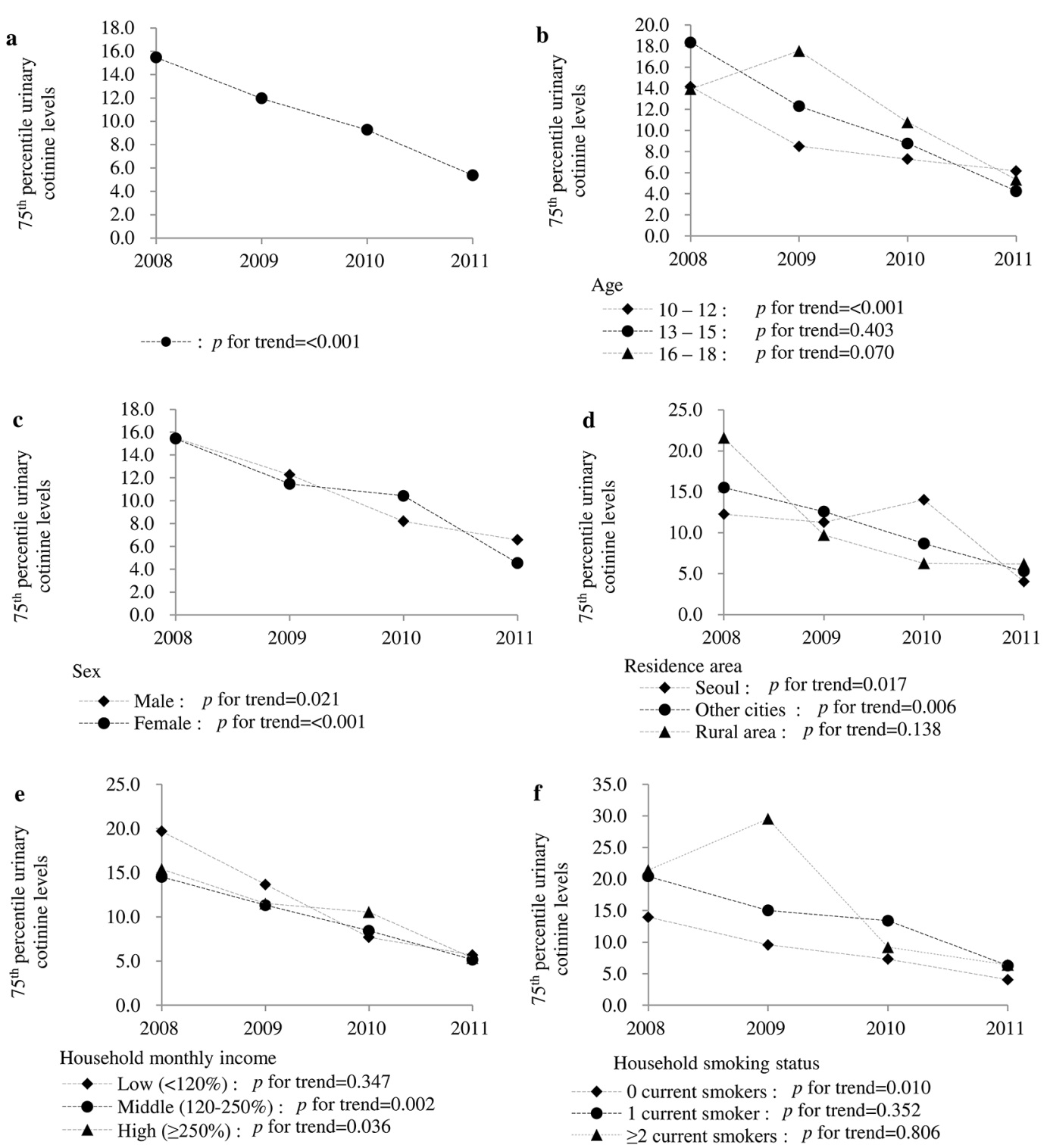

Figure 2 Analysis of urinary cotinine in non-smoking youths from 2008 to 2011. (a) The 75th percentile urine cotinine level of non-smokers showed a significant decreasing trend from 2008 to 2011. When subgroups were divided by (b) age, (c) sex, (d) residence area, (e) household monthly income and (f) household smoker, the 75th percentile urinary cotinine level was significantly decreased in the 10-12-year subgroup, both sexes, all residence area subgroups except the rural area subgroup, middle and high income subgroups and the no household smoker subgroup. Data are presented as the 75th percentile urine cotinine levels; $p$ values for trend were calculated through linear regression.

The threshold value between exposure and non-exposure to ETS among non-smokers has been proposed to be $5-10 \mathrm{ng} / \mathrm{mL}$ because of dietary consumption of nicotine. ${ }^{23} 3031$

In the non-smoking group, 75th percentile urinary cotinine showed a significant reduction from 2008 to 2011. The trends in urinary cotinine level might be due to policy changes, other smoking cessation interventions, school-based cessation programmes and education, and so on. However, there was no national or regional movement in Korea from 2008 to 2010, except the studied policy change.
Since 1995, government-initiated anti-smoking policies have been enacted in Korea, including tobacco tax increases, designated non-smoking indoor areas, restricted advertisement of tobacco products, prohibition of tobacco sales to those less than 19 years of age, warning labels on tobacco packages, diverse anti-smoking campaigns and improved accessibility of cessation treatment; a partial smoking ban was started. It is clear that Korea's government-led anti-smoking movement achieved a substantial reduction in the smoking prevalence rate in men from $67 \%$ in 1998 to $47.7 \%$ in 2008 . A partial smoking ban was expanded to include elevators, 


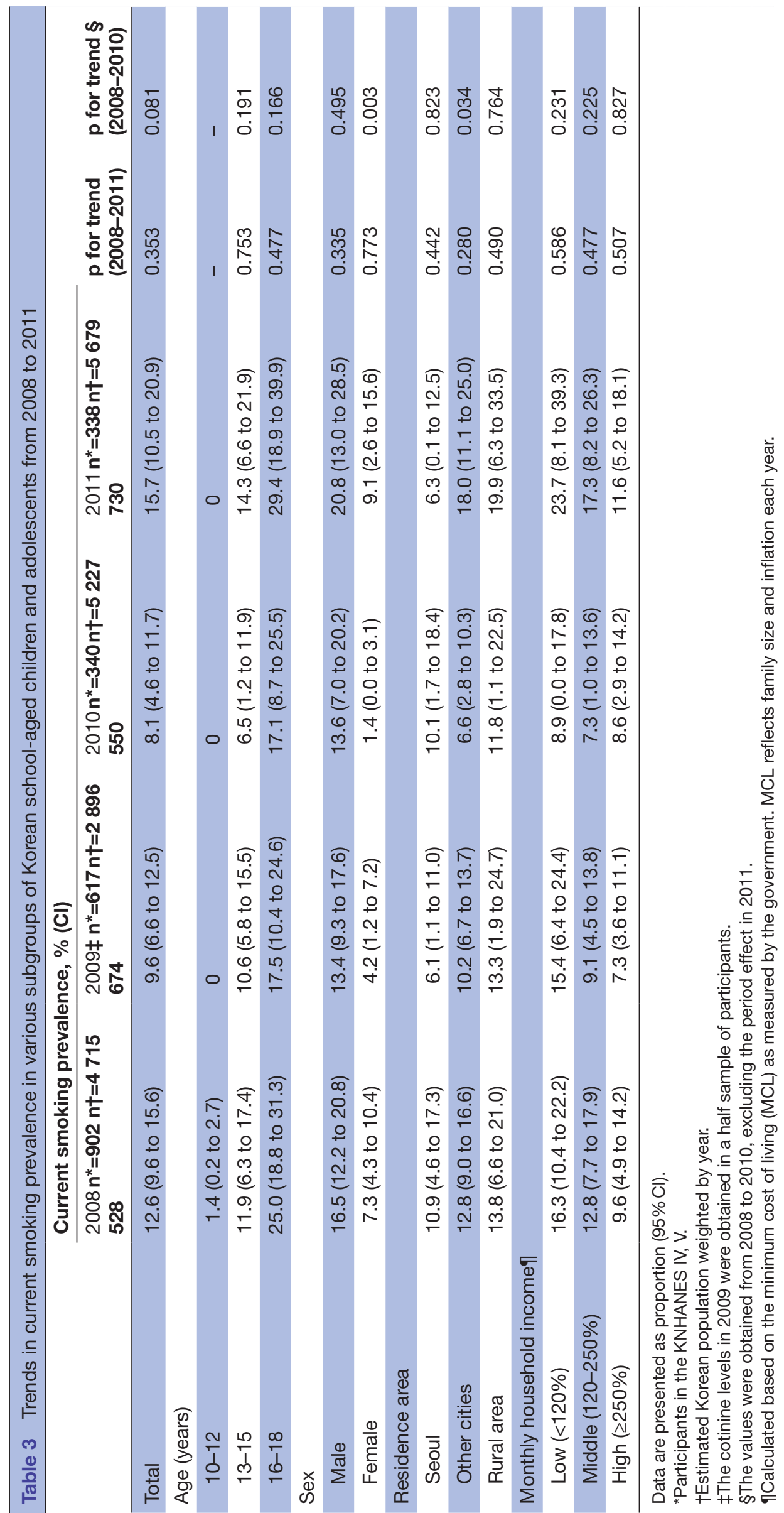


aisles and restrooms in public or large buildings in 2008. The smoking rates among adults remained almost unchanged from 2008 to 2011 (27.3\% and 26.3\%, respectively). ${ }^{11}$ The 75 th percentile urine cotinine level of non-smokers showed a significant decreasing trend from 2008 to 2011 , from 15.47 to $5.37 \mathrm{ng} / \mathrm{mL}$, respectively. The results showed that the partial smoking ban seemed to be effective among highly exposed non-smoking adolescents during the study period.

With the advent of smoking bans, non-smokers who previously felt embarrassed about publicly expressing their distaste for ETS are able to speak up. Facing heightened public hostility toward smoking habits, smokers are likely to revise their preferences regarding smoking. Smoking bans might affect social norms and reduce the number of smokers. ${ }^{32}$

The urinary cotinine level is presented in terms of 75 th percentile instead of median value (figure 2). However, the decreasing pattern in the urinary cotinine level from 2008 to 2011 remained unchanged when the median value was used. The findings suggest that government-initiated anti-smoking policies might have been effective only among highly exposed groups. Residence area was shown to be a risk factor for ETS in school-aged children in the present study. ${ }^{33}$ The lowest levels of urine cotinine in 2008 were observed in children living in Seoul and the highest were in children living in rural areas. This can be explained by the fact that cities such as Seoul are more active in banning smoking than rural areas. However, this gap has been decreasing, which might be an effect of policies supporting the goals of the FCTC, the reduction of socioeconomic inequality in smoking prevalence.

We also found that the number of family members who smoke was another critical factor in ETS exposure. Having a greater number of smokers in the family showed a significant correlation with increased 75th percentile urinary cotinine level. This is because these children tend to be exposed to tobacco smoke in the home as well as in public places. According to one study conducted in $2010,{ }^{14}$ as many as $40.3 \%$ of boys and $41.5 \%$ of girls are exposed to passive smoking at home. Moreover, home smoking is not greatly affected by public policies. Our study found that an increased number of smokers in the family was related to an increase in ETS secondhand smoking and an increase in urine cotinine level. The cotinine level did not decline significantly throughout the survey period in adolescents living with smokers, although a decreasing trend is shown in figure 2.

The current results did not show a statistically significant reduction in smoking rate in adolescents from 2008 to 2011, although there was a trend toward a decrease $(p=0.081)$. The impact of legislative bans on smoking prevalence has shown inconsistent results. ${ }^{34}$ This study did not show significant results, possibly because the data were analysed only over 4 years. The change in prevalence of current smoking was contrary to our expectations. Smoking prevalence in adolescents declined until 2010, then increased in 2011 to twice that of the previous year; this pattern was consistent across subgroups of age, sex, household income and number of household smokers. There was a possibility of information bias or selection bias in adolescents in 2011. However, the increasing trend in smoking rates was consistent across both urinary cotinine and self-reported assessments, suggesting that information bias was not responsible for the increase. There is a possibility of selection bias despite the large representative study population with sampling weights. The smoking rate of adults in 2011 did not show an increasing trend. ${ }^{13}$ These results seem to be affected by factors specific to adolescents during this period.

The sudden increase in the smoking rate in adolescents in 2011 despite the anti-smoking policies might be due to an educational policy begun in late 2010 that also became an important social issue. Increasing public interest regarding student rights led to the Student Human Rights Ordinance in 2010, which came into effect in Gyeonggi-do (one of the rural areas) in 2011. The Student Human Rights Ordinance had not yet taken effect in Seoul in 2011. No increase in smoking rate was found in Seoul in 2011. Unfortunately, the effect of the educational policy on youth could not be evaluated after 2011 since urinary cotinine levels were no longer assessed by the KNHANES, even though the policy was subsequently strengthened.

The essence of the ordinance was the realisation of student human rights by means of securing freedom in several aspects. It included liberalising dressing styles as well as hair length and style and might have significantly affected the smoking prevalence of school-aged children in 2011.

The finding of increased smoking prevalence from 2010 to 2011 and decreased ETS exposure from 2010 to 2011 indicates that the policy has decreased ETS exposure for non-smokers (a high-risk group), but has not affected smokers. The results provide additional evidence for the existing findings. ${ }^{34}$ The smoking prevalence of schoolaged children might be affected by smoking prohibition policies and also by education policies. This suggests that a more integrated approach considering the effect of education policies is needed in order to effectively reduce the smoking prevalence of school-aged children.

One of the limitations of the present study was that we were not able to exclude urinary cotinine from sources other than smoking and ETS. Urinary cotinine is a resulting product of nicotine metabolism. The urinary cotinine level reflects nicotine exposure, but nicotine does not only originate from smoking, but also from certain foods and electronic smoking devices. However, considering that the proportion of urine cotinine obtained from daily food consumption is relatively small (averaging $0.6 \mathrm{ng} / \mathrm{mL}$, maximum $6 \mathrm{ng} / \mathrm{mL}{ }^{23}$ and that it affects all subjects equally, the general trend will not have been changed by this factor.

Another limitation of the present study is that children without urinary cotinine measurements were not included. Although the KNHANES provides nationwide 
data, it only contains data for children with urinary cotinine level results. Thus, even after applying a weight adjustment, there is a possibility that our results do not perfectly represent the whole Korean population. However, urinary cotinine data from 2010 and 2011 were collected by random sampling, not from all subjects in the sample group so the results are independent of smoking habits. Therefore, the population of children without urine cotinine measurements should not significantly alter our results. For further confirmation, we cross-checked self-reported smoking status and other epidemiological characteristics between the urine cotinine-measured group and non-measured group from 2008 to 2011 and found no significant differences.

Potential mechanisms of cigarette smoke-related injury include oxidative stress, inflammation, protease-antiprotease imbalance, impaired repair process and mutagenesis. ${ }^{35}$ Although these processes lead to various results depending on timing, dose of exposure and individual health condition, many studies support the conclusion that the effects on younger people tend to last longer and are more destructive. Moreover, ETS exposure has a profound effect on children's smoking habits when they become adults. Therefore, children's secondhand smoke exposure requires greater attention.

Government-initiated smoke-free policies might reduce urine cotinine levels among school-aged non-smokers. However, as shown in previous studies, the anti-smoking policy did not reduce the effects of home smoking. ${ }^{37} 38$ The fact that data from only Korean adolescents was used must also be taken into consideration when generalising the results. Because all students wore school uniforms in Korea, it might also influence the generalisability of the results. Furthermore, the effect of a partial smoking ban among highly exposed non-smoking adolescents can be combined with other smoking cessation interventions such as school-based cessation programmes and education.

Acknowledgements This research was supported by a grant from the Korea Health Technology R\&D Project through the Korea Health Industry Development Institute (KHIDI), funded by the Ministry of Health and Welfare, Republic of Korea (grant number HI14C1062).

Contributors JK conducted the analyses and wrote the manuscript. HWY guided and supervised the writing of the manuscript. HWY, HJ and JK came up with and proposed the basic idea of the study. $\mathrm{HJ}, \mathrm{JB}, \mathrm{YB}$ and $\mathrm{JL}$ reviewed the manuscript. MP conducted statistical analysis. All authors contributed editorial comments on the manuscript.

\section{Competing interests None declared.}

Ethics approval This study received approval from the Institutional Review Board of The Catholic University of Korea (MC15EISI0097).

Provenance and peer review Not commissioned; externally peer reviewed.

Data sharing statement Extra data can be accessed via the Dryad data repository at doi:10.5061/dryad.b7040

Open Access This is an Open Access article distributed in accordance with the Creative Commons Attribution Non Commercial (CC BY-NC 4.0) license, which permits others to distribute, remix, adapt, build upon this work non-commercially, and license their derivative works on different terms, provided the original work is properly cited and the use is non-commercial. See: http://creativecommons.org/ licenses/by-nc/4.0/ (c) Article author(s) (or their employer(s) unless otherwise stated in the text of the article) 2017. All rights reserved. No commercial use is permitted unless otherwise expressly granted.

\section{REFERENCES}

1. Lee BE, Ha EH. Exposure to environmental tobacco smoke among South Korean adults: a cross-sectional study of the 2005 Korea National Health and Nutrition Examination Survey. Environ Health 2011;10:29.

2. Hwang $\mathrm{SH}$, Hwang JH, Moon JS, et al. Environmental tobacco smoke and children's health. Korean J Pediatr 2012;55:35-41.

3. Mackay DF, Irfan MO, Haw S, et al. Meta-analysis of the effect of comprehensive smoke-free legislation on acute coronary events. Heart 2010;96:1525-30.

4. Tan CE, Glantz SA. Association between smoke-free legislation and hospitalizations for cardiac, cerebrovascular, and respiratory diseases: a meta-analysis. Circulation 2012;126:2177-83.

5. Veeranki SP, Mamudu HM, Anderson JL, et al. Worldwide neversmoking youth susceptibility to smoking. J Adolesc Health 2014;54:144-50.

6. Veeranki SP, Mamudu HM, Zheng S, et al. Secondhand smoke exposure among never-smoking youth in 168 countries. J Adolesc Health 2015;56:167-73.

7. Hahn EJ, Rayens MK, York N, et al. Effects of a smoke-free law on hair nicotine and respiratory symptoms of restaurant and bar workers. J Occup Environ Med 2006;48:906-13.

8. Ellingsen DG, Fladseth G, Daae HL, et al. Airborne exposure and biological monitoring of bar and restaurant workers before and after the introduction of a smoking ban. J Environ Monit 2006;8:362-8.

9. Callinan JE, Clarke A, Doherty K, et al. Legislative smoking bans for reducing secondhand smoke exposure, smoking prevalence and tobacco consumption. Cochrane Database Syst Rev 2010;4:Cd005992.

10. Fernández MF, Artacho-Cordón F, Freire C, et al. Trends in children's exposure to second-hand smoke in the INMA-Granada cohort: an evaluation of the Spanish anti-smoking law. Environ Res 2015;138:461-8.

11. Choi S, Kim Y, Park S, et al. Trends in cigarette smoking among adolescents and adults in South Korea. Epidemiol Health 2014;36 e2014023

12. Khang $\mathrm{YH}$, Yun SC, Cho HJ, et al. The impact of governmental antismoking policy on socioeconomic disparities in cigarette smoking in South Korea. Nicotine Tob Res 2009;11:262-9.

13. Cho HJ. The status and future challenges of tobacco control policy in Korea. J Prev Med Public Health 2014;47:129-35.

14. Katanoda K, Jiang Y, Park S, et al. Tobacco control challenges in East Asia: proposals for change in the world's largest epidemic region. Tob Control 2014;23:359-68.

15. Chung C-E. Complex sample design effects and inference for Korea National Health and Nutrition Examination Survey data. Korean $J$ Nutr 2012;45:600-12.

16. Centres for Disease Control and Prevention of Korea. Korea National Health and Nutrition Examination Survey. 2011 http://knhanes.cdc. go.kr/ (accessed 5 Mar 2012).

17. Myong JP, Kim HR, Choi SE, et al. Dose-related effect of urinary cotinine levels on bone mineral density among Korean females. Osteoporos Int 2013;24:1339-46.

18. Bala MM, Strzeszynski L, Topor-Madry R, et al. Mass media interventions for smoking cessation in adults. Cochrane Database of Systematic Reviews 2013;6:CD004704.

19. Brown J, Michie S, Raupach T, et al. Prevalence and characteristics of smokers interested in internet-based smoking cessation interventions: cross-sectional findings from a national household survey. J Med Internet Res 2013;15:e50.

20. Durkin S, Brennan E, Wakefield M. Mass media campaigns to promote smoking cessation among adults: an integrative review. Tob Control 2012;21:127-38.

21. Connor Gorber S, Schofield-Hurwitz S, Hardt J, et al. The accuracy of self-reported smoking: a systematic review of the relationship between self-reported and cotinine-assessed smoking status. Nicotine Tob Res 2009;11:12-24.

22. Jung S, Lee IS, Kim SB, et al. Urine cotinine for assessing tobacco smoke exposure in Korean: analysis of the Korea National Health and Nutrition Examination Survey (KNHANES). Tuberc Respir Dis 2012;73:210-8.

23. Haufroid V, Lison D. Urinary cotinine as a tobacco-smoke exposure index: a minireview. Int Arch Occup Environ Health 1998;71:162-8. 
24. Kim S, Jung A. Optimum cutoff value of urinary cotinine distinguishing South Korean adult smokers from nonsmokers using data from the KNHANES (2008-2010). Nicotine Tob Res 2013;15:1608-16.

25. Kim KY, Myong JP, Kim HR, et al. Dose-related effect of urinary cotinine levels on pulmonary function among Korean women. Int $J$ Tuberc Lung Dis 2014;18:622-7.

26. Benowitz NL, Hukkanen J, Jacob P 3rd. Nicotine chemistry, metabolism, kinetics and biomarkers. Handb Exp Pharmacol 2009;192:29-60.

27. Kim Y, Choi S, Chun C, et al. Data resource profile: the Korea Youth Risk Behavior Web-based Survey (KYRBS). Int J Epidemiol 2016;45:dyw070-6.

28. Hassanzad M, Khalilzadeh S, Eslampanah Nobari S, et al. Cotinine level is associated with asthma severity in passive smoker children. Iran J Allergy Asthma Immunol 2015;14:67-73.

29. Saulyte J, Regueira C, Montes-Martínez A, et al. Active or passive exposure to tobacco smoking and allergic rhinitis, allergic dermatitis, and food allergy in adults and children: a systematic review and meta-analysis. PLoS Med 2014;11:e1001611.

30. Davis RA, Stiles MF, deBethizy JD, et al. Dietary nicotine: a source of urinary cotinine. Food Chem Toxicol 1991;29:821-7.

31. Florescu A, Ferrence R, Einarson T, et al. Methods for quantification of exposure to cigarette smoking and environmental tobacco smoke: focus on developmental toxicology. Ther Drug Monit 2009;31:14-30.

32. Stuber J, Galea S, Link BG. Smoking and the emergence of a stigmatized social status. Soc Sci Med 2008;67:420-30.

33. Yi O, Kwon HJ, Kim D, et al. Association between environmental tobacco smoke exposure of children and parental socioeconomic status: a cross-sectional study in Korea. Nicotine Tob Res 2012;14:607-15

34. Frazer K, Callinan JE, McHugh J, et al. Legislative smoking bans for reducing harms from secondhand smoke exposure, smoking prevalence and tobacco consumption. Cochrane Database Syst Rev 2016;2:Cd005992.

35. Centers for Disease Control and Prevention. The health consequences of smoking: a report of the Surgeon General. Georgia: US Department of Health and Human Service, 2004

36. Henderson AJ. The effects of tobacco smoke exposure on respiratory health in school-aged children. Paediatr Respir Rev 2008;9:21-8.

37. Ye X, Chen S, Yao Z, et al. Smoking behaviors before and after implementation of a smoke-free legislation in Guangzhou, China. BMC Public Health 2015;15:982.

38. Kairouz S, Lasnier B, Mihaylova T, et al. Smoking restrictions in homes after implementation of a smoking ban in public places. Nicotine Tob Res 2015;17:41-7. 